\title{
MEDICAL CASES DEMONSTRATED DURING A RECENT M.R.C.P. COURSE
}

\author{
By C. WORSTER-DROUGHT, M.A., M.D., F.R.C.P., \\ (Physician to the West End Hospital for Nervous Diseases) \\ and N. G. HULBERT, M.A., M.D., M.R.C.P. \\ (Medical Registrar to the West End Hospital for Nervous Diseases)
}

\section{CASE I.-PARALYSIS OF THE THIRD CRANIAL NERVE DUE TO SECONDARY DEPOSIT FROM PRIMARY BRONCHIAL CARCINOMA IN A MYOPATHIC SUBJECT}

A man, aged 46, was seen early in 1942 complaining of drooping of right eyelid and double vision of two weeks' duration. Wasting and weakness of all shoulder girdle muscles had been present for twenty years.

History.-The muscles of the upper arms and of both shoulder girdles began to waste at about the age of 26 , but have only slowly become worse. Two weeks ago the right eyelid began to droop, and, about the same time, he complained of double vision. In addition he has had intermittent frontal headache for the last month, and an occasional cough during the past two years. There was no history of a similar condition in his family; he is married but has no children.

On examination he shows complete ptosis of the right eyelid; the right pupil is larger than the left; there is no reaction to light in the right pupil and only slight reaction to accommodation-convergence. The right eye deviates outwards, and there is no movement in any ocular muscle supplied by the third nerve. The fundi are normal, and there is a brisk corneal reflex on both sides. The other cranial nerves are normal. There is considerable wasting of all muscles of both shoulder girdles, including the deltoids, latissimus dorsi, trapezii, rhomboids, supra- and infra-spinati and pectorales majores. In addition, both biceps and radio-brachiales are paresed. The radial jerks are absent, and all arm reflexes either reduced or absent. There is some weakness of both quadriceps and hamstrings as well as in the anterior tibial group of muscles in both legs. The knee jerks are present and about equal; the ankle jerks are absent and plantar reflexes flexor; sensation is normal. The heart is normal; pulse 70; B.P. I30/70. A few scattered rhonchi in the lungs, but no other abnormality.

Investigation, subsequent progress and commentary.-The distribution of the muscle weakness and wasting clearly pointed to a diagnosis of a myopathy, approximating to Erb's juvenile type (primary muscular dystrophy); it did not appear possible that this condition had any connection with the third nerve palsy, which was clearly the result of complete involvement either of the nucleus or the nerve trunk itself. Syphilitic basi-meningitis was the first condition to exclude, and this was done by finding a negative W.R. in the blood and cerebrospinal fluid. The latter showed a pressure of only roo $\mathrm{mm}$. with slow rise and fall; 25 small lymphocytes per c.mm.; total protein of $80 \mathrm{mg}$. per cent and a trace of globulin. The increased cell count suggested a slight inflammatory disturbance and the raised protein was compatible with this condition or with a neoplasm. The absence of a raised cerebrospinal fluid pressure was rather against a primary cerebral tumour. An aneurism of the circle of Willis had also to be considered, but the increased cell count was rather against this diagnosis. The accessory nasal sinuses were found clear both on clinical and on X-ray examination. A secondary carcinomatous deposit in the brain was also possible, as such a tumour replaces cerebral tissue rather than compresses it, and, therefore, one would not expect the cerebrospinal fluid pressure necessarily to be raised. Examination of the prostate revealed no abnormality. An X-ray examination of the chest, however, showed that the left side of the diaphragm was raised and immobile while the right side moved normally. Both hila were enlarged, and a dense shadow was seen in the region of the left hilum, strongly indicative of primary bronchial carcinoma.

Note.-The patient died a few weeks after demonstration, and post-mortem examination (by Dr. Carnegie Dickson) showed a lesion around some bronchiectatic cavities in the left lung, sections of which showed typical bronchial carcinoma undergoing necrosis with much softening. In addition a soft tumour filling up the third ventricle causing a bulging of the infundibulum was found in the brain. This involved the right third nerve, which was considerably smaller than the left. On microscopical examination the cerebral tumour was typical of secondary bronchial carcinoma. 


\section{CASE II.-PESUDOTABES SYPHILITICA}

A man, aged 52, complaining of weakness of hands and legs with numbness, tingling and occasional pains in the legs. Duration six weeks.

History of present condition.-About six months ago he began to complain of occipital headache, especially when lying down, and, about the same time, occasional buzzing in the right ear. Two months ago he noticed double vision which lasted for about three weeks. For the past six weeks he has complained of tingling and some numbness in the arms and legs, especially towards evening, together with pain across the shoulders when lifting his arms; occasional pains in the legs and frequent cramps, more often in the left calf than in the right.

On examination.-Pupils equal and react normally to light and to accommodationconvergence. Fundi normal; other cranial nerves normal. Vibration sense much reduced in legs, but sensation otherwise normal. Slight wasting of outer side of left thenar eminence and of first left interosseus. Radial and supinator jerks cannot be obtained. Both the arms and legs show some general muscular wasting; all movements are present but appear somewhat reduced in power. Knee and ankle jerks absent on both sides and plantar reflexes flexor. Abdominal reflexes sluggish. Gait inclined to be unsteady but co-ordination good on the whole, and he remains steady in the Romberg position. Heart normal; pulse 6o; blood pressure I40/90. Blood count shows no abnormality. Blood W.R. positive. Cerebrospinal fluid shows 2 lymphocytes per c.mm.; total protein of Ioo mg. per cent; trace of globulin; W.R. negative and Lange of low luetic type-0orr221000.

Commentary.-The symptoms and physical signs indicate a peripheral neuritis or a neuro-radiculitis, rather than tabes dorsalis. Against the latter diagnosis is the absence of an Argyll-Robertson pupil and the fact that deep pressure sensation is moderately good; further, co-ordination is only slightly impaired. Also the cerebrospinal fluid result is by no means typical of tabes dorsalis. On the other hand the considerable increase of the cerebrospinal fluid protein with a normal cell count is compatible with a diagnosis of neuro-radiculitis of Guillain-Barré type, and this diagnosis might be said to have been confirmed by this result but for the strongly positive blood W.R. It is suggested, therefore, that this case represents an example of the so-called "Pseudo-tabes syphilitica," a condition which results from syphilitic involvement of both anterior and posterior spinal nerve roots-in fact, a syphilitic neuroradiculitis. This diagnosis seems more probable than the alternative hypothesis-that the case is one of Guillain-Barré syndrome occurring in a subject whose W.R. was already positive from previous specific infection. The final test will lie in the result of anti-syphilitic treatment, for, with arsenical and bismuth therapy, the prognosis is good.

\section{CASE III.-SYPHILITIC THIRD NERVE PALSY WITH NEGATIVE BLOOD WASSERMANN REACTION}

Man, aged 53, complaining that his right eye had shut.

History of the condition was that five weeks before he had had diplopia lasting for 'two days, after which the eyelid had gradually closed over a period of three days. The diplopia, however, persisted when the lid was held open. disease.

Past history.-There were no special illnesses and there was no history of venereal

Family history.-His first wife was divorced, having had two healthy sons and two miscarriages. His second wife was alive and well, with three children by a previous marriage.

On examination. Right pupil is larger than the left and shows no direct or consensual reaction to light and no reaction to accommodation. The left pupil is small, and reacts briskly, both directly and consensually to light and also to accommodation and convergence. The right eye deviates outwards a little beyond the mid-line. The right sixth nerve is spared, as shown by the futher voluntary lateral deviation of the eye. The downward and rotatory movement produced by the superior oblique muscle can also be elicited, showing that the fourth nerve is intact. The right eyelid is completely ptosed. The rest of the central nervous system is normal and the blood pressure $120 / 80$.

Investigations.-Cerebrospinal fluid: pressure IIo mm., 54 cells per c.mm., which were practically all small lymphocytes; total protein $80 \mathrm{mg}$. per cent; slight excess of globulin; strongly positive Wassermann reaction, over 8 m.h.d. of complement being deviated; Lange 
curve 455544322I. Blood W.R. completely negative, with no delay in the rate of haemolysis. The blood W.R. was therefore repeated the following week, and was again completely negative.

\section{Treatment.}

(I) A course of arsenic, in the form of Acetylarsan $(2 \mathrm{cc}$. for the first injection, followed by $3 \mathrm{cc}$. for eleven subsequent injections). This is given either by intramuscular or subcutaneous injection, and so makes for convenience in treatment, and at the same time a rather more gradual absorption of the arsenic, which is of some advantage in neurosyphilis.

(2) With this he was given bismuth in the form of $\frac{1}{2} \mathrm{cc}$. Bismotab weekly.

(3) Potassium iodide orally.

Diagnosis and commentary.-This case presented a complete unilateral external and internal ophthalmoplegia of the right third nerve. It was, therefore, due to a peripheral lesion of the third nerve, rather than a nuclear lesion, as the nucleus of the third nerve consists of several parts arranged near the mid-line, and so is unlikely to be completely destroyed on one side alone. Supranuclear lesions of the oculo-motor nerves show themselves as a loss of conjugate deviation rather than of individual movements of the eyes. The diagnosis first to be considered is a syphilitic basi-meningitis involving the third nerve, as proved to be present in this case. The main differential diagnosis was between other causes of pressure on the nerve in its course along the base of the skull. The most interesting feature of this case was the marked changes in the cerebrospinal fluid with the negative blood W.R., which presents an obvious pitfall in general practice.

\section{CASE IV.-SUBACUTE COMBINED DEGENERATION OF THE CORD, WITH UNUSUAL RECOVERY}

Man, aged 44, first seen on December Io, I94I, complaining of being unable to walk.

History.- - He lived alone with an elderly landlady, and consequently had no relatives to comment on his appearance. For one year he had had pains in the calves and weakness of the legs. For six months the weakness of the legs had become more pronounced, the feet had felt numb and dead, and there was some swelling of the ankles as well as pain in the hands. For two weeks he had had diarrhoea, with four to five watery motions a day, but containing no mucus, blood or pus. This had made him feel very weak, and he was admitted having collapsed, though not fainted, in the street.

On examination.- $-\mathrm{He}$ was very pale, and his cerebration was slow. Cranial nerves were normal; both arm reflexes were very brisk. His legs were very spastic, flexed and adducted into a scissors position. The knee and ankle jerks were much increased, both plantar responses were extensor, vibration sense was absent, but tendon sense was present in the legs; the calves were very tender to pressure. The blood pressure was $130 / 70$; the bladder was distended, and he was at first incontinent, having to be catheterised.

Investigations.-Cerebrospinal fluid: pressure $150 \mathrm{~mm}$; fluid otherwise normal with negative W.R. Blood W.R. negative. Blood urea $46 \mathrm{mg}$. per cent; blood count $\mathrm{Hb} 58$ per cent; R.B.Cs. 2,550,000; colour index I·I5; anisocytosis and hyperchromia of the red cells. W.B.Cs. 7,700; polymorphs 76 per cent; lymphocytes I8 per cent; large monocytes 5 per cent; Eosiniphils I per cent. No abnormal white cells. Fractional test meal showed no free $\mathrm{HCl}$.

Treatment.-He was treated with

(I) Intramuscular liver extract, 2 cc. every other day.

(2) Aneurin hydrochloride (vitamin $B_{\mathrm{I}}$ ), $5 \mathrm{mg}$. daily by injection and $2 \mathrm{mg}$. t.d.s. by mouth.

(3) Ferri et ammon. cit. in a mixture, gr. 60 t.d.s.

(4) Massage and exercises.

On this treatment he improved remarkably, his weight, which was $8 \mathrm{st}$. I2 lb. on January I, I942, rose to Io st. II lb. on April I2, I942. On January 9, I942, he was just able to stand without assistance, and walk a few steps if supported by both hands, but he continued to show a tendency to scissors gait. In the Romberg position he was able to stand with eyes open, but not with the eyes closed. The calves were no longer tender on pressure. By March I9, I942, he was quite clear mentally, free from pain, and walking fairly well with a stick. By April I5, I942, his blood count was: haemoglobin 88 per cent, R.B.Cs. 5,050,000, colour index $0 \cdot 87$, W.B.Cs. Io,800. His mental state was normal, and he was able to walk without a stick, 
and to go up and down stairs. He was discharged April I6, r942, has has since obtained skilled work, earning $£ 4$ Ios. a week, after having been unemployed for some time before his illness.

\section{Diagnosis.}

(I) Pernicious anaemia and achlorhydria.

(2) Peripheral neuritis of the legs, shown particularly by the original tenderness of the calves.

(3) Subacute combined degeneration of the cord, in which the pyramidal damage overshadowed that of the posterior columns to a remarkable degree, producing a spastic paraplegia with scissoring of the legs.

(4) Mental apathy due to the cerebral anaemia.

Commentary.- The remarkable improvement in this case is of particular interrest as it has been stated that the spinal cord lesions are irreversible, and that any clinical improvement is due to recovery from the peripheral neuritis. This view may be difficult to refute in those cases where the posterior column damage predominates, as is more usual, but here the improvement was in the spasticity (lateral columns), and of such a degree that a bedridden man, with "scissored" legs, was enabled to resume active employment.

\section{CASE V.-SUBACUTE ARTERIOPATHIC ENCEPHALOPATHY}

Charles H., aged 58, first seen March 4; I942.

History of present condition.-Five weeks ago he reported to his own doctor complaining of difficulty in remembering things and feeling generally "out of sorts." According to his wife and doctor, he was quite well until five or six weeks ago; he performed his work of commercial traveller as well as usual and discussed the war situation with his habitual keenness and acuity. Since then his mental and physical condition has deteriorated steadily to his present semi-mute and quasi-vegetative general state.

On examination.-He appears somewhat dazed and facile, with slow and limited voluntary movement. He shows perseveration of speech and in actions to command. Thus, when asked his name, he says after a minute or two "Hoby"; when asked the day of the week, he repeats "Hoby," and continues repeating his name in answer to any following questions. When asked to show his tongue, he does so after some hesitation; when asked to show his teeth, he will again protrude his tongue and repeat this action several times. Similarly on taking off his shoes and socks, he will put on his shoes to command without using his hands but will attempt to put on his socks in a similar fashion. This action is repeated several times no matter what is the subsequent command. He can give no coherent or proper account of himself and is unable to present any flow of speech. It appears from his facial expression that his intellectual activity is equally reduced.

The pupils are equal and react somewhat sluggishly to light and normally to accommodation. Optic discs clear and bloodvessels not obviously pathological. Speech limited to syllables such as "ah," "oh," and "ee." Otherwise he does not speak at all, but is occasionally heard to say "nice" when food is presented to him. Other cranial nerves are normal. A bilateral grasp reflex is present; he tends to close his hands over any object placed in them and to grasp it very firmly, e.g. the examiner's hand is firmly gripped until forcibly withdrawn. Arm jerks are brisk and equal on the two sides, with a suggestion of slight resistance to passive movement. He is able to walk in a slow and careful manner with small steps. Knee and ankle jerks moderately brisk but equal; plantar reflexes flexor. Abdominal reflexes sluggish. Coarse tremor of hands and unsteadiness in the Romberg position. Tendency to urinary retention. Pulse rate 70; heart sounds faint, no demonstrable enlargement. No gross thickening of palpable bloodvessels; blood pressure r40/95. Blood W.R. negative. Cerebrospinal fluid shows normal pressure; two small lymphocytes per c.mm.; total protein $45 \mathrm{mg}$. per cent; faintest detectable trace of globulin; W.R. and Lange reactions negative. Urine contains no albumin or sugar; blood urea $36 \mathrm{mg}$. per cent; X-ray of skull shows no abnormality.

Commentary.-The mental state and physical signs indicate a gross organic lesion of the brain, more particularly of the frontal lobes. A tumour of the frontal lobe, especially if situated near the mid-line in the left frontal lobe and tending to compress the right cerebral hemisphere, has to be considered; against this is the absence of any rise in the cerebrospinal fluid pressure and the presence of an average protein content as well as the absence of papilloedema. A rapidly developing form of Alzheimer's disease appears the most probable diagnosis. An air encephalography was carried out. This showed general dilitation of the lateral ventricles, particularly on the left side; there was no deviation of the inter-ventricular 
septuim. This result was compatible with diffused atrophic changes in the brain and with a diagnosis of Alzheimer's disease or of arteriopathic encephalopathy.

Subsequent progress.-His condition continued to deteriorate, and by March I7 the plantar reflexes were mainly extensor in type and were accompanied by contraction of the hamstrings and withdrawal of the leg. The arms tended to be held flexed across the chest. He was incapable of speech and could not swallow; he merely smiled fatuously when a nasal feed was run into the oesophagus and then made movement of chewing. On March 20 th he was found to show the rare phenomenon of a definite "grasp reflex" in both feet, as well as the grasp reflex of the hands; this suggested a further extension of the damage in the frontal lobes. By March 22nd he was unable to walk and the limbs showed increased muscular rigidity with periodic twitching; there were also occasional epileptiform seizures. Death occurred on March 25th.

Note.-On post-mortem examination (Dr. Carnegie Dickson) the dura mater was distinctly thickened and firmly adherent to the interior of the skull. The general surface of the brain showed considerable atrophy of the convolutions, especially over the frontal lobes, with exaggeration of the sulci and slight thickening of the arachnoid. After fixation in Pick's fluid, the brain was examined and a semi-recent thrombosis of the right internal carotid and middle cerebral arteries was found; the vertebral arteries were unequal in size, the right being small and the left larger, with its walls showing advanced atheroma. The basillar artery formed by their union was of distinctly small size, as well as the vessels forming the circulus arteriosus, with numerous patches of atheromatous degeneration. Atheroma and irregular narrowing of most of the larger cerebral arteries was also demonstrated. The heart was reduced in size, especially the left side, and the aorta and both coronary arteries showed well-marked patchy atheroma. The mitral valve curtains showed extensive patchy atheroma as well as irregular fibrous thickening along their margins, but no stenosis. The tricuspid valve curtains showed similar changes in lesser degree. Further histological examination of the brain showed no appearances in the nerve cells, axons or other structures to suggest Alzheimer's disease. On serial horizontal section the whole brain showed changes indicating chronic arterial degeneration leading to some degree of general cerebral atrophy. The case, therefore, is a good example of rapid cerebral arteriopathy showing pronounced mental and neurological changes with practically no clinical signs in the circulatory system to indicate the true nature of the malady.

CASE VI.-MOTOR NEURONE DEGENERATION AS A CAUSE OF PSEUDO-BULBAR PALSY

A man, aged 50, complaining of weakness of the legs to such an extent that he had become bedridden, and also of weakness of the arms and difficulty in talking.

History.- - Two years ago his left leg had tended to drag. One year later his right leg had begun to get weak and he started to fall frequently. Three months before admission he had become unable to walk at all. One month ago he had noticed difficulty in speaking, but had had no difficulty in swallowing.

On examination.- Speech slurred, slow and drawling. Tongue protruded stiffly but shows no wasting; the palate moves rather slowly. He shows an exaggerated jaw-jerk, which responds to very light percussion. He has weakness and wasting of the small muscles of both hands, and also of the forearms and biceps. Fibrillary tremors are seen in the muscles of the arms. All the arm reflexes are greatly exaggerated. The abdominal reflexes are absent. The legs show some wasting and he can only just raise them from the bed; there is bilateral footdrop and the legs are adducted. The muscles of the legs show fibrillary tremors. The knee and ankle jerks are exaggerated, the plantar responses are difficult to elicit owing to paralysis of the extensors, but appear to be flexor. The rest of the central nervous system is normal. Blood pressure I6o/Iro.

Investigations.-Cerebrospinal fluid shows $70 \mathrm{mg}$. total protein but no other abnormality. Blood W.R. negative.

Diagnosis and commentary.- This case falls into the group known as "motor neurone degeneration.". He. shows the features of progressive muscular atrophy in the wasting of the small muscles of the hands and the fibrillary tremors in the arms and legs. The pyramidal tract damage and degeneration of the cerebral motor cortex of amyotrophic lateral sclerosis is shown by the spastic paralysis and increased deep reflexes. The dysarthria, however, is not due to a bulbar palsy, but to spasticity of the muscles of speech. As these have a bilateral cortical representation, such a pseudo-bulbar palsy entails damage to the upper motor neurones of the cranial nerve nuclei concerned on both sides of the body. Pseudo-bulbar paralysis may also be seen in patients who have had two "strokes" affecting both sides of the body. 